\title{
Research on the Strategies of Infiltrating Emotional Education in College English Teaching
}

\section{Yun Wang}

Teaching and Research Institute of Foreign Languages, Bohai University, Jinzhou, 121013, China

30404786@qq.com

Keywords: college English teaching; emotional education; emotional factors; application strategies

\begin{abstract}
Paying attention to emotional education can improve the quality and effectiveness of English teaching. In return, English teaching can help students develop positive, healthy and good emotions. Based on humanism theory, constructivism theory and emotional educational psychology theory, this paper analyzes the emotional factors affecting college English teaching, such as motivation, anxiety, interest, attitude and self-confidence, and puts forward strategies of the emotional education of college English: change teaching concepts; give full play to the emotional motivation in language learning; cultivate students' interest in learning; stimulate students' learning motivation; emotionally deal with teaching content; effectively develop emotional resources; learn to appreciate students and enhance students' self-confidence; establish diversified evaluation system; enhance students' self-confidence.
\end{abstract}

\section{Introduction}

Emotional education means that in the process of classroom teaching, teachers should create a harmonious teaching environment that is conducive to student learning, properly handle the relationship between emotion and cognition in the teaching process, give full play to the positive role of emotional factors, and enhance students' positive through emotional communication. The emotional experience, cultivate and develop students' rich emotions, stimulate students' curiosity and exploration spirit, and encourage students to form independent and complete personality and personality characteristics. Emotional education is both a kind of teaching model and teaching strategy. The goal of emotional education includes three aspects: one is to cultivate students' social feelings; the other is to improve students' self-regulation ability; and the third is to help students to positively relate themselves to the environment and the relationship generated emotional experience between them.

Emotional education, as the whole process of radiation teaching and the educational awareness and operation mode of each link, plays an extremely important role in the overall development of students' quality. Improving the quality and innovation mode is the eternal theme of the development of higher education. Throughout the years of college English teaching reform, it is still focused on cognition and neglect of emotions. Basically, from the perspective of teachers, it ignores the initiative and creativity of students, and does not pay attention to students. Emotional characteristics, students' emotional problems such as anxiety, fear, nervousness, suspicion and disgust, lack of effective solutions. Emotional attitude is an important factor affecting students' learning and development. Maintaining positive emotional attitude is the key to English learning. Guided by the basic theory, this paper uses the combination of empirical research and qualitative analysis to address the practical problems existing in college English teaching, and proposes the guiding plan and implementation countermeasures of infiltration emotional education in college English teaching to improve the quality of English teaching.

\section{Theoretical Basis of Infiltrating Emotional Education in College English Teaching}

The theoretical basis provides theoretical guidance for directing research. The research is based 
on the following theoretical basis:

(1) Humanistic theory. Emphasis on the human factors in the learning process, learners are the main body of learning, teaching activities should be student-centered, respect the personal experience of students, and create all conditions and opportunities to help students build positive emotions, making students' learning process more interesting. An important principle of humanistic theory is to attach importance to learners' wishes, emotions, needs and values. The learning process is not only a process of acquiring knowledge, skills and intellectual development, but also enabling students to explore emotions, correctly articulate values and attitudes, and develop maximum potential to achieve the best realm, so that the personality is improved and developed.

(2) Constructivism theory. The process of foreign language learning is also the process of emotional construction. Learners' interests, self-confidence and anxiety are constantly being constructed. Knowledge construction is accompanied by emotional construction, and emotional construction also affects knowledge construction. In the process of foreign language learning, cognition and emotion interact with each other, restrict each other, and are inseparable. Emotional development is only possible in the interaction between cognition and emotion. The ideal foreign language learning process should enable students to construct positive emotions, continuously stimulate learning interest, reduce foreign language learning anxiety, enhance self-confidence, and cultivate students' positive emotions in foreign language learning.

(3) Emotional educational psychology theory. In the teaching process, teachers and students not only transmit cognitive information, but also emotional information exchange. The emotional factors in teaching exist in teachers, students and textbooks. These three basic elements interact and communicate with each other to form dynamic emotional communication. Loops work together throughout the teaching process. The active role of the emotional persuasion function is conducive to the promotion of students' internalization of teaching requirements and content; the positive role of emotional coordination function is beneficial to improve the interpersonal relationship between students and students, teachers and students, and form a good interpersonal environment. .

\section{Emotional Factor of Influence College English Teaching}

Emotion itself is difficult to quantify, which determines that emotional education in college English teaching is an abstract, complex and implicit process, relying on the grasp of ambient emotions, college English curriculum emotions and students' emotional characteristics. The emotional factors are complex. This paper selects the following five emotional factors to analyze briefly:

(1) Motivation. Motivation is the internal driving force that directly promotes individual activities. Individual activities, whether simple or complex, are regulated and dominated by motivation. Learning motivation generates learning desires, directs learning actions to certain goals, determines learning effort, and helps learn perseverance. English learning motivation is the desire and motivation of learners to learn English. It is divided into intrinsic motivation and extrinsic motivation. Intrinsic motivation is more important than extrinsic motivation. External motivation is an external factor that affects English learning, usually to obtain material rewards or avoid punishment; intrinsic motivation is to be interested in English learning, and to be satisfied and happy in the learning process. Intrinsic motivation is motivated when students are able to determine learning objectives, learning methods, and learning outcomes. If the student has an intrinsic motivation, learning itself is the reward. External motivation is associated with short-term success, and intrinsic motivation is associated with long-term success.

(2) Anxiety. Anxiety is a kind of inner uneasiness or unfounded fear that lacks obvious objective reasons. It is an emotional reaction that occurs when faced with challenges, difficulties or dangers. Anxiety is often associated with a danger or threat that is about to come, subjectively showing tension and discomfort. Anxiety is divided into promotion and obstruction according to its effects. The former motivates students to overcome difficulties, challenges learning tasks, strives to overcome anxiety, and is associated with students' competitive consciousness. It is a positive emotion and can improve learning outcomes under moderate anxiety. But excessive anxiety wastes 
energy for thinking and remembering, affecting learning or work. In college English teaching, students are worried about not knowing English, or have no confidence in the accurate use of English, fear of being ugly in front of teachers or classmates, and worry that the test will not pass, there will be varying degrees of anxiety, affecting normal understanding and expression.

(3) Interest. Interest is the psychological tendency of people to know something or engage in certain activities. It is based on the need to understand and explore the outside world. It is an important motivation to promote understanding of things and to explore the truth. Interest has long been formed by individuals in their lives, and It is occasionally motivated by certain things under certain circumstances. Interest is divided into direct interest and indirect interest. Direct interest refers to interest in the activity process. For example, students are interested in English learning itself; indirect interest refers to interest in the outcome of the activity process. For example, students are not interested in English learning itself. However, if you learn English well, you can graduate, go abroad or find a better job, which has an indirect interest. Direct interest and indirect interest can be transformed into each other, and indirect interest is transformed into more persistent direct interest, which is more in line with the needs for college English teaching .

(4) Attitude. Attitude is the stable psychological tendency of an individual to a specific subject, and it contains the subjective evaluation of the individual and the resulting behavioral tendencies. Attitude determines the potential motivation of behavior, can promote individuals to resolve psychological conflicts, increase tolerance to setbacks, and achieve desired goals. Students' attitudes toward learning include attitudes toward the curriculum, attitudes toward learning materials, and attitudes toward teachers and schools. Learning attitude is closely related to the learning effect. In the school situation, if other conditions are basically equal, students with good learning attitudes have relatively good academic performance. English learning attitude is the tendency to understand, emotion, emotion and behavior in English learning. If you have a positive attitude towards English learning, you will have more input, and you will actively think about the problem and improve your English. Teachers should try to change the negative learning attitude of students.

(5) Self-confidence. Self-confidence is a psychological state that reflects the ability to complete the trust level of an activity. It is a psychological state that actively expresses self-worth, self-respect and self-understanding. Self-confidence affects students' learning, competition, employment and achievement, and is of great significance to the healthy growth of students. Without self-confidence, even the best intelligence can hardly achieve the desired learning effect. In college English learning, students with strong self-confidence will take the initiative to practice language, take risks, be afraid of making mistakes, and progress quickly, leading to stronger self-confidence and a virtuous circle and positive chain reaction. On the contrary, if you do not have the confidence, do not dare to actively practice language, fear to make mistakes, and dare not take risks, you will lose many opportunities to communicate in English, and the learning effect is not satisfactory. Moreover, it will weaken confidence and produce greater negative feelings.

\section{Application Strategies of Infiltrating Emotional Education in College English Teaching}

Emotional education plays an important role in teaching. Focusing on emotional education can improve the quality and effectiveness of English teaching. In return, English teaching can help students develop positive and healthy emotions. In view of the problems existing in college English teaching, referring to the relevant literature, the strategies for penetrating emotional education in college English teaching proposed in this paper are as follows:

(1) Change the concept of teaching and give full play to the emotional motivation in language learning. One of the important functions of human language is to promote interpersonal communication. To achieve interpersonal communication, it is inevitable to involve people's emotional attitudes. Emotional attitudes need to be expressed and transmitted through language to a large extent, to communicate emotions, to solve emotional problems, and to use language. Proper and rational use of language helps to communicate emotions, promote friendship and mutual understanding, and improve interpersonal relationships. Emotional attitudes are not only inextricably linked with language learning, but also affect language learning directly or indirectly in 
many aspects, and the impact on English learning is more obvious. Positive emotions, lively and cheerful personality, help students actively participate in language learning activities and gain more learning opportunities; strong motivation for learning, strong interest in learning, and the spirit of taking risks will help improve learning outcomes; The will and strong self-confidence help students overcome difficulties in language learning. On the contrary, many negative emotional attitudes affect the language learning process.

(2) Cultivate students' interest in learning and stimulate students' motivation for learning. "Interest is the best teacher", interest is one of the strong motivations of people's activities, can stimulate people's creative enthusiasm and curiosity. To arouse students' interest in learning, first of all, enrich the teaching content, provide students with knowledge, fun and authentic teaching content, so that students can understand more about the political, economic, cultural and local customs of English-speaking countries. Secondly, the English teaching methods are diversified. They pay attention to both language rules and language use. According to the teaching objects, teaching environment and teaching content, different teaching methods centered on students are used to increase the interest of the classroom and motivate the students. Learning motivation is the fundamental driving force of learning activities, which affects students' learning effect and enthusiasm. English teachers should try to improve the charm of English, so that students can clearly recognize the importance of learning English well and improve the temptation to learn English well, so that they can maintain a strong motivation to learn, and students will invest more. For English learners, English can be seen as a goal. The greater the value of the goal, the greater the incentive value given to the individual.

(3) Emotional processing of teaching content and effective development of emotional resources. Emotional and colorful teaching content can stimulate students' desire for inquiry and participation, enhance students' thinking level, improve students' memory and internalization efficiency, expand language input, and promote students' mental development. The emotional processing of the teaching content, the teacher from the emotional dimension of the processing content and processing, so that the teaching content in the process of presenting to students, play an active role in the emotional aspects. First, using emotion as the mean to skillfully organize teaching content, adjust students' mentality, and mobilize the unique functions of emotional factors; second, use emotion as the goal, effectively use the emotional resources in teaching content, and stimulate students' positive emotional experience to cultivate lofty sentiment. This requires the teacher to design the classroom teaching situation according to the actual situation of the students and the emotional factors contained in the teaching materials in the course of preparing the lesson, so that the teaching content is novelty, exploratory and enjoyment. For those content that has no emotional color, we must try to give emotional color, make the ordinary and boring teaching content living and interesting, and give rise to students' emotional resonance.

(4) Teachers learn to appreciate students and enhance their self-confidence. Appreciation is an art, a quality, a virtue. One of the most basic needs of people is to be eager to be appreciated by others. As a teacher, be good at appreciating students. Every student is eager to get the teacher's attention and praise. Therefore, every student should be respected and every student should be appreciated during the teaching process. "What is missing in the world is not beauty, but the eyes good at discovering." Knowing how to appreciate students will help students to develop talents, in return it may be the failure of education. English teachers must pay attention to evaluation methods, respect students, encourage students, accept and appreciate students. In the process of English teaching, be good at listening to students' opinions, paying attention to students' emotions, admiring and praising students' advantages, and also tolerating their shortcomings. When students answer questions or display language, do not over-correct pronunciation or errors, but guide the topic, encourage students to express their opinions in language that suits their level, encourage natural English communication between students, and enhance students' self-confidence. When students are unable to answer questions, teachers should also give appropriate and positive guidance to maintain students' self-esteem.

(5) Establish diversified evaluation system to enhance students' self-confidence. First, adhere to 
the combination of formative evaluation and summative evaluation. Formative evaluation is based on the evaluation of continuous observation, recording and reflection of the whole process of learning, helping students to effectively regulate the learning process; summative evaluation is the evaluation of the judgment effect after the end of the teaching activity. Formative assessments provide timely and regular feedback, and summative assessments demonstrate the ultimate impact of classroom instruction and learning processes. Second, master the time of timely evaluation and delay evaluation. Timely evaluation can enable students to understand learning outcomes and progress in a timely manner, and enhance the motivation to explore unknown areas; delay evaluation uses students' expectation psychology, delays evaluation time appropriately, and leaves students time and space for free thinking. Mastering the time of them will help students to solve their own advantages, enhance self-confidence, clear their efforts, and have positive expectations for learning. Third, the vertical evaluation is mostly used, and the comparative evaluation between the horizontal students is rarely used. The horizontal evaluation ignores the students' English basic and intellectual factors, and it is easy for students to lose confidence, discourage students' self-esteem, and participate in teaching activities. Teachers should listen to each student's speech and carefully study the language of evaluation so that students at every level can have a correct understanding of themselves, constantly summarize and reflect, and adjust their mentality to the higher goal.

\section{Conclusion}

Emotional attitude is an important factor affecting students' learning and development. Maintaining positive emotional attitude is the key to English learning. It is of great practical significance to carry out research on this topic in the context of the current low level of interest in English learning for college students, the effectiveness of English teaching, and the low quality of English teachers. Using the implementation countermeasures of infiltration emotional education in college English teaching proposed in this paper, assisting teachers to flexibly infiltrate emotional education in the process of English teaching, stimulating and cultivating students' strong interest in learning English, and further promoting students' cognitive ability in English. Develop students' potential, improve students' ideological and moral quality and good interpersonal relationship, and then develop students' self-emotional control ability, and promote positive emotional experience in English learning, application and practice, and gradually form independent and complete personality characteristics, which will definitely format for students. It will play a positive role in the development of the future society.

\section{References}

[1] K, F, Wu, "The Application of Affective Education in Middle School English Teaching," Overseas English, vol. 15, no. 4, pp. 12-13, 2014.

[2] J. D. Guo, "Components of affective engagement with English learning and its effect on academic achievement," Modern Foreign Languages, vol. 41, no. 1, pp. 55-65, 2018.

[3] J. Hao, "The design of emotional objectives for College English teaching," Journal of Jilin Institute of Chemical Technology, vol. 34, no. 10, pp. 75-78, 2017.

[4] W. Y. Zhang, "On the infiltration of emotional teaching in college English teaching," Popular Science, vol. 27, no. 10, pp. 142-143, 2017.

[5] Y. N. Liu, "On the application of positive affective factors in College English classroom teaching," Heilongjiang Science, vol. 9, no. 4, pp. 68-69, 2018.

[6] H. Yi, "The causes and countermeasures of emotional loss in network English teaching," English on Campus, vol. 30, no. 35, pp. 58-59, 2016.

[7] L. J. Liu, "A Study of the Effect of WeChat on College Students' Affective Factors in English Learning," Theory and Practice of Education, vol. 38, no. 9, pp. 49-51, 2018. 